\title{
Enterococci in farm-manufactured Pecorino and goat cheese
}

\author{
Beniamino Cenci-Goga 1,2*, Musafiri Karama ${ }^{2}$, Saeed El-Ashram ${ }^{3,4}$, Cristina Saraiva ${ }^{5,6}$, Juan García-Díez ${ }^{5}$, Athana- \\ sios Chalias ${ }^{7}$ and Luca Grispoldi ${ }^{1}$
}

1 Dipartimento di Medicina Veterinaria, Università degli Studi di Perugia, Italy; beniamino.cencigoga@unipg.it

2 Faculty of Veterinary Science, Department of Paraclinical Sciences, University of Pretoria,

Onderstepoort 0110, South Africa; musafiri.karama@up.ac.za

3 School of Life Science and Engineering, Foshan University, Foshan Guangdong 528231, China; saeed elashram@yahoo.com

4 Faculty of Science, Kafrelsheikh University, Kafr el-Sheikh, 33516, Egypt; saeed elashram@yahoo.com

5 Veterinary and Animal Research Centre (CECAV). University of Trás-os-Montes e Alto Douro, 5001-801, Vila Real, Portugal; crisarai@utad.pt; juangarciadiez@utad.pt

6 Department of Veterinary Sciences, School of Agrarian and Veterinary Sciences, University of Trás-os-Montes e Alto Douro, 5000-801. Vila Real, Portugal; crisarai@utad.pt

7 European Food Safety Authority, EU-FORA Programme, 43126 Parma, Italy; a.chalias@gmail.com

* Correspondence: Beniamino Cenci Goga; beniamino.cencigoga@unipg.it ; Tel.: +39 0755857973

\begin{abstract}
Enterococci are enteric organisms which are commonly isolated from ewe and goat's milk production in Umbria, Italy. For years enterococci have been considered as microorganisms only indicative of inadequate hygienic practices or exposure of the food to conditions that would permit multiplication of other undesirable bacteria. However, enterococci largely occur in many cheeses, and are now considered to be usual components of their typical microflora. They play a major role in cheese ripening due to lipolytic, proteolytic and caseinolytic activities. Enterococci have been also shown to be involved in food poisoning outbreaks although only E. faecalis has been demonstrated to cause changes in dairy products, thus being the only species of concern in dairy production. The aim of this study was to was to investigate the evolution of enterococci during the production and ripening of Pecorino cheese made with two different cheesemaking processes and characterize Enterococcus spp. isolates all along the cheesemaking and ripening process.
\end{abstract}

Keywords: Enterococcus, QPS, GRAS, safety, milk, cheese

\section{Introduction}

Enterococci are gram-positive bacteria and may fit within the general definition of lactic acid bacteria. With regard to safety and according to the Qualified Presumption of Safety (QPS) list from the European Food Safety Authority (EFSA) (https://www.efsa.europa.eu/en/topics/topic/qps, Enterococcus species are neither recommended for the QPS list [1] nor have GRAS status [2], in spite of recent scientific knowledge allowing differentiation of commensal from pathogenic strains [3-5]. Modern classification techniques resulted, back in 1980s, in the transfer of some members of the genus Streptococcus, notably some of the Lancefield's group D streptococci, to the new genus Enterococcus [6]. Enterococci can be used as indicators of fecal contamination and have been implicated in outbreaks of foodborne illness. On the other hand, they have been ascribed a beneficial or detrimental role in foods [3-5]. In processed meats, enterococci may survive heat processing and cause spoilage, though in certain cheeses the growth of enterococci contributes to ripening and development of product flavor [3,7]. Some enterococci of food origin produce bacteriocins that exert anti-Listeria activity [8]. Enterococci are used as probiotics 
to improve the microbial balance of the intestine, or as a treatment for gastroenteritis in humans and animals $[4,5,9,10]$. On the other hand, enterococci have become recognized as serious nosocomial pathogens causing bacteraemia, endocarditis, urinary tract and other infections. This is in part explained by the resistance of some of these bacteria to most antibiotics that are currently in use. Resistance is acquired by gene transfer systems, such as conjugative or nonconjugative plasmids or transposons. Virulence of enterococci is not well understood but adhesins, haemolysin, hyaluronidase, aggregation substance and gelatinase are putative virulence factors. It appears that foods could be a source of vancomycin-resistant enterococci $[4,11,12]$.

Regardless these considerations Enterococci are commonly found in milk and cheese [13] and there are two divergent opinions about the presence of enterococci in cheese. One is that enterococci should be considered more suitable than others groups commonly used as indicators of unhygienic procedures in food processing and handling (e.g. Enterobacteriaceae). This is related to their high heat resistance and salt tolerance [14]. The other opinion is that enterococci have a possible contribution to the ripening of cheese due to their lipolytic, proteolytic and caseinolytic activities [15]. Moreover it has been stressed their contribution to flavor producing due to the attitude of produce acetoin, diacetyl and acetaldehyde [15].

Pecorino and goat cheeses are typical Italian cheeses made usually with whole raw ewe's or raw goat's milk, without starter culture addition. Thus, only bacteria's milk contribute to ripening changes in the cheese. In previous works the possibility of using heat treated milk with added autochthonous starter cultures was compared with traditional cheesemaking technology from raw milk [7]. Even though food hygienic aspects were improved, enterococci were found to be present at the end of the ripening in cheeses made with both cheesemaking processes, possibly playing a weighty role in determining the quality of the finished product.

The aim of this work was to investigate the evolution of enterococci during the production and ripening of Pecorino cheese made with two different cheesemaking processes and characterize Enterococcus spp. isolates all along the cheesemaking and ripening process.

\section{Materials and Methods}

\section{General}

The experiment was carried out on three farms in Umbria, farm A, has 500 Sardinian ewes, farm B has 200 Sardinian ewes, farm C has 80 Saanen goats. In farm A and B milk is collected with a milking machine and automatically filtered before the cheesemaking. In farm $\mathrm{C}$ goats are hand milked and the milk is filtered through a linen cloth.

Milk from each farm was collected, analyzed and subsequently used to produce Pecorino or goat cheese. On each farm two different cheesemaking processes were carried out from raw milk and from heat-treated milk to which the autochthonous cultures were added as a starter. These cultures have been characterized in previous works [9,16-20]. Each cheesemaking was replicated three times. According to this experimental procedure there were 18 manufacturing processes: 12 from raw milk and 12 from heat-treated milk. Cheese manufacturing

Cheese was made from ewes and goats milk obtained from both evening and morning milking. The main steps of cheesemaking process were: milk coagulation in a tinned copper vat occurred at $37^{\circ} \mathrm{C}$ within about $30^{\prime}$ by adding liquid calf rennet (Lima, Perugia, Italy, titre 1:10.000). The curd was cut into nut-sized granules (10 to $20 \mathrm{~mm})$, then stirring for 5 minutes, heated at $42-43^{\circ}$. After a pause of 5 to 10 minutes the curd was put into molds ( $20 \mathrm{~cm}$ diameter by $8 \mathrm{~cm}$ high), pressed by hand for a few seconds, drained for 18 to 20 hours and salted in brine $\left(20 \% \mathrm{NaCl} \mathrm{w} / \mathrm{v}\right.$, at $12-15^{\circ} \mathrm{C}$ for $\left.30 \mathrm{~h}\right)$. The cheeses were ripened in non-conditioned storage rooms at $12-15^{\circ} \mathrm{C}$ and $83-87 \%$ RH for 60 days (40 days for goat cheeses). 
Heat treatment (where applied) provided a heating before the rennet addition. Raw milk was heated to $65-66^{\circ} \mathrm{C}$ for 3-4 min in a double wall stainless steel vat. The thermic cycle $55-65-55^{\circ} \mathrm{C}$ (during heating and cooling) took about $14 \mathrm{~min}$. After further cooling to $42{ }^{\circ} \mathrm{C}$, the starter was added at $42^{\circ} \mathrm{C}$ at a final concentration of $2 \%$ (as a full-coagulated $24 \mathrm{~h}$ culture in sterile milk)

\section{Sampling}

The following samples were taken on each farm: raw milk, heat-treated milk (where applied), curd, 7 days cheese, 30 days cheese, full-ripened cheese. Triplicate samples were collected, transported to the laboratory in chilled containers and analyzed on the same day. Sampling was made according to ISO 5538:2004 [21].

Bacterial counts

The following groups were evaluated:

- total viable count: pour plates of Plate Count Agar (Difco, Detroit, Mi, USA), were incubated at $30^{\circ} \mathrm{C}$ for $72 \mathrm{~h}$; all colonies were counted;

- Enterobacteriaceae: pour plates of Violet Red Bile Agar (Difco) were incubated at $32^{\circ} \mathrm{C}$ for $48 \mathrm{~h}$; all pink to red colonies, irrespective of diameter or presence/absence of zone of precipitation were counted;

- enterococci: surface-inoculated plates of Barnes Agar (Biolife, Milano, Italy) were incubated at $44^{\circ} \mathrm{C}$ for $72 \mathrm{~h}$; all pink, red or maroon colonies, irrespective of diameter, were counted.

\section{Isolation and identification of enterococci}

Two to five colonies from each sample were sub-cultured from Barnes medium into brain heart infusion broth (BHI, Difco) at $37^{\circ} \mathrm{C}$ for $24 \mathrm{~h}$ and then tested for the following characteristics: cell morphology after Gram staining, presence of catalase, growth in bileesculin-azide agar (Coccosel agar, BioMéhrieux, Marcy-l'Etoile, France) at $37^{\circ} \mathrm{C}$, growth in $6.5 \% \mathrm{NaCl} \mathrm{BHI}$ agar (Difco) at $37^{\circ} \mathrm{C}$, growth in the presence of $4 \%$ bile salts (Coccosel agar, Biolife, with added $4 \%$ bile salts) at $37^{\circ} \mathrm{C}$, haemolysis type on tryptic soy agar (Biolife) to which $5 \%$ of ram blood was added, at $37^{\circ} \mathrm{C}$.

Complementary biochemical tests were performed on colonies grown on blood agar using the API 20 STREP (BioMéhrieux): hydrolysis of hippurate and arginine, production of $B$-galactosidase, acid production from ribose, L-arabinose, mannitol, sorbitol, lactose, trehalose, inulin, raffinose, starch and glycogen. Computer program APILAB (VERSION?) (BioMéhrieux) was used for the results.

\section{Antbiotics susceptibility}

Enterococcus spp. isolates were tested for antimicrobial susceptibility against a panel of 12 antimicrobials by the disk diffusion method (Kirby Bauer Test) as described by the Clinical and Laboratory Standards Institute [22] The following antimicrobials were tested: amikacyn $30 \mathrm{mg}$, amoxycillin/clavulanic acid $30(20+10) \mathrm{mg}$, ampicillin $10 \mu \mathrm{g}$, ceftriaxone $30 \mu \mathrm{g}$, chloramphenicol $30 \mu \mathrm{g}$, ciprofloxacin $5 \mu \mathrm{g}$, kanamycin $30 \mu \mathrm{g}$, sulphamethoxazole 25 $\mu \mathrm{g}$, sulphamethoxazole/trimethoprim $25 \mu \mathrm{g}$, tetracycline $30 \mu \mathrm{g}$, ticarcillin $75 \mu \mathrm{g}$, vancomicyn $30 \mu \mathrm{g}$. This antimicrobial panel was selected to test the major groups of antimicrobials. Briefly, frozen isolates were thawed and cultured in BHI broth (Bio-Rad) at 35 to $37^{\circ} \mathrm{C}$ for $24 \mathrm{~h}$. A portion of the culture broth was inoculated into $6 \mathrm{~mL}$ of $0.9 \%$ sterile physiological saline solution until a turbidity of $2 \mathrm{McF}$ arland was reached. Using a sterile swab, the solution was spread on Muller-Hinton agar plates (Oxoid). Antimicrobial disks (Oxoid) were placed on Muller-Hinton agar plates which were incubated at $37^{\circ} \mathrm{C}$ for 18 to $24 \mathrm{~h}$. At the end of incubation, the diameters of the growth inhibitory zones were measured, and these were interpreted using specific CLSI tables whereby the bacterium is classified as sensitive, intermediate or resistant [22].

\section{Results and discussion}


Results of the determination made on Pecorino and goat cheese during manufacture and ripenin are given in tables 1-2-3-4-5-6.

Changes in total viable counts and Enterobacteriaceae.

The changes observed were similar to those observed previously [7]. The differences observed on the three farms comprised a range of variability which is common to on-farm cheesemaking (Table 1).

The total mesophilic aerobes in raw milk ranged from $\log 5.9 \log \mathrm{cfu} \mathrm{ml}^{-1}$ in farm A to $\log 7.54 \log \mathrm{cfu} \mathrm{ml}^{-1}$ in farm C. At the early stage of production of cheeses made with raw milk, counts increased up to 1 week and then decreased. In the cheesemaking processes from heat-treated milk added with autochthonous starter cultures bacterial population in milk, after the treatment, was reduced to $\log 3.06 \log \mathrm{cfu} \mathrm{ml}^{-1}$ in farm A, $\log 4.56$ $\log \mathrm{cfu} \mathrm{ml}^{-1}$ in farm B and $\log 4.91 \log \mathrm{cfu} \mathrm{ml}^{-1}$ in farm C. After the treatment counts showed the same evolution described for cheeses made with raw milk.

Enterobacteriaceae in raw milk ranged from $3.9 \log \mathrm{cfu} \mathrm{ml}^{-1}$ in farm A to $3.9 \log \mathrm{cfu}$ $\mathrm{ml}^{-1}$ in farm B. In cheeses made with raw milk Enterobacteriaceae increased up to curd production and then decreased being not detectable or at low concentration at the end of the ripening. On farm $B$ and $C$ bacterial reduction was observed on 1 week cheese whilst on farm $\mathrm{A}$ an additional growth occurred in cheese during the first week of ripening, after which there was a decrease in population. Enterobacteriaceae were not detectable in fullripened cheese made with raw ewe's milk whilst they were detected from full-ripened cheese made with raw goat's milk. In cheeses made with heat-treated milk with added autochthonous starter cultures, Enterobacteriaceae underwent great reduction in heattreated milk being not detectable in farm $\mathrm{A}$, whilst they were only partially reduced in farm B and C (4.22 log of reduction in farm B and 2.91 in farm C). Although heavy curd recontamination always occurred, no Enterobacteriaceae were detectable in full-ripened cheese made with heat-trated ewe's milk, whilst they were still detected in cheeses made with heat-trated goat's milk.

\section{Behaviour of enterococci}

Enterocci counts in milk were always lower than $4 \log \mathrm{cfu} \mathrm{ml}^{-1}$. The changes observed were similar to those observed previously [7]. At the early stage of production of cheeses made with raw milk, counts increased up to 1 week and than slightly decreased. In the cheesemaking processes from heat-treated milk with added autochthonous starter cultures no evident reduction of enterococci population was observed after the treatment. After the heat treatment counts showed the same behavior described for cheeses made with raw milk.

\section{Identification}

One-hundred strains of enterococci were identified. Forty-six from farm A, thirtytwo from farm B and twenty-two from farm C. Sixty-nine were identified as Enterococcus faecium, twenty-two as Enterococcus durans, seven as Enterococcus faecalis and two as Enterococcus casseliflavus (Tables 2 and 3). Enterococcus faecium was found more frequently on farm A $(80.4 \%)$ and on farm B $(68.8 \%)$, whilst on farm C more than $95 \%$ of the isolates consisted of Enterococcus faecium and Enterococcus durans altogether. No strains of Enterococcus faecalis were found on Farm A, whilst Enterococcus casseliflavus was found only on farm B.

Bacterial cells under microscopic observation after Gram staining appeared Gram negative, in pairs or in short chains, ovoid elongated in direction of the chain. All strains were catalase negative. This result together with cells morphology confirmed the identification of the strains as belonging to the genus Streptococcus. Enterococci were identified as such on the basis of their growth in the presene of bile-esculine, $6.5 \%$ of $\mathrm{NaCl}$ solution, and $4 \%$ bile salts, and on the basis of the idrolysis of the arginine. TTC reduction on Barnes medium differenziated E. faecalis from E. faecium. Infact culture grown in the presence of triphenyl tetrazolium chloride (TTC) on Barnes medium were white or with a red center and white border. The former were presumptively identified as E. faecium and the latter 
as E. faecalis prior to biochemical tests with API 20 Strep (BioMéhrieux). No strains were B-haemolitic.

The principal physiological and biochemical characteristics of the isolates are given on Table 4.

\section{Antbiotics susceptibility}

The antimicrobial susceptibility test data are shown in Table 5 and 6 . High percentages $(>80 \%)$ of susceptible strains were found for amoxycillin/clavulanic acid, ampicillin, chloramphenicol, sulphamethoxazole, sulphamethoxazole/trimethoprim, ticarcillin, vancomicyn. A high prevalence of resistance strains (>30\%) was observed for amikacin, ciprofloxacin, ceftriaxone, kanamicin, tetracycline. It is important to note that $5 \%$ of the srains (one strain of E. durans and 4 strains of E. faecium all isolated from farm B) were resistant to vancomycin. In the last two decades, Enterococci have become major nosocomial pathogens. An increasing number of these infections are due to enterococci that are resistant to vancomycin. Accurate detection of vancomycin-resistant enterococci (VRE) is important so that appropriate therapy and infection control measures may be instituted, including veterinary surveillance [23].

\section{Conclusion}

In Pecorino and goat cheese the ripening processes are the result of the natural microbiological contamination of milk and of the characteristics cheesemaking technology. Therefore, not only lactic acid bacteria but also other bacterial groups, such as enterococci, must be considered. This study demonstrated that, regardless the cheesemaking technology, heavy curd recontamination occurs and that enterococci are always detected at high concentration at the end of ripening. A large proportion of isolates are also resistant to antibiotics and this pose the question whether microorganism belonging to Enterococcus spp. can be awarded the QPS or GRAS status.

Author Contributions: “Conceptualization, B.C.G. and L.G.; methodology, B.C.G. and L.G.; formal analysis, B.C.G. and L.G.; writing - original draft preparation, B.C.G.; writing-review and editing, B.C.G., M.K., S.E.S.; supervision, C.S. and J.G.D..; project administration, B.C.G.; funding acquisition, B.C.G. All authors have read and agreed to the published version of the manuscript."

Funding: "This research was funded by EFSA, European Food Safety Authority, grant number GP/EFSA/ENCO/2018/05_GA6".

Acknowledgments: The authors express sincere appreciation to members of Polyglot, Perugia, Italy, for a careful reading and comments on the manuscript.

Conflicts of Interest: “The authors declare no conflict of interest."

\section{References}

1. Hazards, E.Panel o.B. Scientific Opinion on the update of the list of QPS-recommended biological agents intentionally added to food or feed as notified to EFSA. EFSA Journal 2017, 15, e04664, doi:https://doi.org/10.2903/j.efsa.2017.4664.

2. Huys, G.; Botteldoorn, N.; Delvigne, F.; De Vuyst, L.; Heyndrickx, M.; Pot, B.; Dubois, J.-J.; Daube, G. Microbial characterization of probiotics-Advisory report of the Working Group "8651 Probiotics" of the Belgian Superior Health Council (SHC). Molecular Nutrition \& Food Research 2013, 57, 1479-1504, doi:https://doi.org/10.1002/mnfr.201300065.

3. Dapkevicius, M.D.; Sgardioli, B.; Câmara, S.P.A.; Poeta, P.; Malcata, F.X. Current Trends of Enterococci in Dairy Products: A Comprehensive Review of Their Multiple Roles. Foods 2021, 10, doi:10.3390/foods10040821.

4. Graham, K.; Stack, H.; Rea, R. Safety, beneficial and technological properties of enterococci for use in functional food applications - a review. Critical Reviews in Food Science and Nutrition 2020, 60, 3836-3861, doi:10.1080/10408398.2019.1709800. 
5. Hanchi, H.; Mottawea, W.; Sebei, K.; Hammami, R. The Genus Enterococcus: Between Probiotic Potential and Safety Concerns-An Update. Frontiers in Microbiology 2018, 9, 1791.

6. Schleifer, K.H.; Kilpper-Bälz, R. Transfer of Streptococcus faecalis and Streptococcus faecium to the Genus Enterococcus nom. rev. as Enterococcus faecalis comb. nov. and Enterococcus faecium comb. nov. International Journal of Systematic and Evolutionary Microbiology 1984, 34, 31-34, doi:https://doi.org/10.1099/00207713-34-1-31.

7. Clementi, F.; Cenci-Goga, B.; Trabalza Marinucci, M.; Di Antonio, E. Use of selected starter cultures in the production of farm manufactured goat cheese from thermized milk. Italian Journal of Food Science 1998, 10, 41-56.

8. Franz, C.M.A.P.; Van Belkum, M.J.; Holzapfel, W.H.; Abriouel, H.; Gálvez, A. Diversity of enterococcal bacteriocins and their grouping in a new classification scheme. FEMS Microbiology Reviews 2007, 31, 293-310, doi:10.1111/j.15746976.2007.00064.x.

9. Cenci-Goga, B.T.; Karama, M.; Sechi, P.; Iulietto, M.F.; Novelli, S.; Selvaggini, R.; Mattei, S. Growth Inhibition of Selected Microorganisms by an Association of Dairy Starter Cultures and Probiotics. Italian Journal of Animal Science 2015, 14, 3745, doi:10.4081/ijas.2015.3745.

10. Grispoldi, L.; Giglietti, R.; Traina, G.; Cenci-Goga, B. How to Assess in vitro Probiotic Viability and the Correct Use of Neutralizing Agents. Frontiers in Microbiology 2020, 11, 204.

11. Cenci-Goga, B.T.; Crotti, S.; Costarelli, S.; Rondini, C.; Karama, M.; Bennett, P. Detection of tet(M) Gene from Raw Milk by Rapid DNA Extraction Followed by a Two-Step PCR with Nested Primers. Journal of Food Protection 2004, 67, 2833-2838, doi:10.4315/0362-028X-67.12.2833.

12. Werner, G.; Coque, T.M.; Franz, C.M.A.P.; Grohmann, E.; Hegstad, K.; Jensen, L.; van Schaik, W.; Weaver, K. Antibiotic resistant enterococci-Tales of a drug resistance gene trafficker. International Journal of Medical Microbiology 2013, 303, 360379, doi:https://doi.org/10.1016/j.ijmm.2013.03.001.

13. Tsanasidou, C.; Asimakoula, S.; Sameli, N.; Fanitsios, C.; Vandera, E.; Bosnea, L.; Koukkou, A.-I.; Samelis, J. Safety Evaluation, Biogenic Amine Formation, and Enzymatic Activity Profiles of Autochthonous Enterocin-Producing Greek Cheese Isolates of the Enterococcus faecium/durans Group. Microorganisms 2021, 9, doi:10.3390/microorganisms9040777.

14. Sojeong, H.; lt; sup; gt; 1t; sup; gt; Jungmin, L.; 1t; sup, et al. Genomic Insight into the Salt Tolerance of \&lt;em\&gt;Enterococcus faecium\&lt;/em\&gt; \&lt;em\&gt;Enterococcus faecalis\&lt;/em\&gt; and \&lt;em\&gt;Tetragenococcus halophilus\&lt;/em\&gt. J. Microbiol. Biotechnol. 2019, 29, 1591-1602, doi:10.4014/jmb.1908.08015.

15. Marilley, L.; Casey, M.G. Flavours of cheese products: metabolic pathways, analytical tools and identification of producing strains. International Journal of Food Microbiology 2004, 90, 139-159, doi:https://doi.org/10.1016/S0168-1605(03)00304-0.

16. Cenci-Goga, B.T.; Karama, M.; Sechi, P.; Iulietto, M.F.; Grispoldi, L.; Selvaggini, R.; Ceccarelli, M.; Barbera, S. Fate of selected pathogens in spiked «SALAME NOSTRANO» produced without added nitrates following the application of NONIT ${ }^{\mathrm{TM}}$ technology. Meat Science 2018, 139, 247-254, doi:https://doi.org/10.1016/j.meatsci.2018.02.002.

17. Cenci-Goga, B.T.; Karama, M.; Sechi, P.; Iulietto, M.F.; Novelli, S.; Selvaggini, R.; Barbera, S. Effect of a novel starter culture and specific ripening conditions on microbiological characteristics of nitrate-free dry-cured pork sausages. Italian Journal of Animal Science 2016, 15, 358-374, doi:10.1080/1828051X.2016.1204633.

18. Sechi, P.; Iulietto, M.F.; Mattei, S.; Traina, G.; Codini, M.; Cenci-Goga, B.T. In vitro activity of a formulation of lactic acid bacteria of dairy origin and probiotics vs. selected pathogens. 2014; Vol. 185, pp 82-82.

19. Sechi, P.; Iulietto, M.F.; Mattei, S.; Traina, G.; Codini, M.; Cenci-Goga, B.T. Effect of a formulation of selected dairy starter cultures and probiotics on microbiological, chemical and sensory characteristics of swine dry-cured sausages. 2014; Vol. 185, pp 83-83.

20. Cenci-Goga, B.T.; Rossitto, P.V.; Sechi, P.; Parmegiani, S.; Cambiotti, V.; Cullor, J.S. Effect of selected dairy starter cultures on microbiological, chemical and sensory characteristics of swine and venison (Dama dama) nitrite-free dry-cured sausages. Meat Science 2012, 90, 599-606, doi:https://doi.org/10.1016/j.meatsci.2011.09.022. 
21. ISO CH. ISO 5538:2004 [IDF 113:2004] Milk and milk products - Sampling - Inspection by attributes. ISO CH: 2004.

22. CLSI. Clinical and Laboratory Standards Institute Guidelines, 2011. Clinical and Laboratory Standards Institute (CLSI), Wayne,PA. 2011.

23. European Centre for Disease Prevention Control. Surveillance of antimicrobial resistance in Europe 2018. ECDC Stockholm: 2019.

1. 